\title{
MCDA stakeholder workshops
}

\author{
T. Duranova ${ }^{1, *}$, E. van Asselt ${ }^{2}$, T. Müller ${ }^{3}$, J. Bohunova $^{1}$, C.J.W. Twenhöfel ${ }^{4}$ and R.C.G.M. Smetsers ${ }^{4}$ \\ 1 VUJE-VUJE, a.s., Trnava, Slovak Republic. \\ 2 WFSR - Wageningen Food Safety Research, Wageningen, The Netherlands. \\ ${ }^{3}$ KIT - Karlsruhe Institute of Technology, Eggenstein-Leopoldshafen, Germany. \\ ${ }^{4}$ RIVM - National Institute for Public Health and the Environment, Bilthoven, The Netherlands.
}

\begin{abstract}
Within the CONFIDENCE project, comprehensive methods have been developed for better support of decision making under uncertain conditions, mainly by use of Multi Criteria Decision Analysis (MCDA). While MCDA in general was available for use in the radiological crisis management community, no method of analysing uncertain conditions and supporting robust decision making under these conditions was available. During the CONFIDENCE project, the existing MCDA tool was improved and enhanced to deal with these requirements. For providing solid and reliable decision support for such a situation as a radiological emergency, the evaluation of decision-support tools by the stakeholders and their feedback is important, especially when considering their heterogeneous background caused by e.g. living in different countries. Therefore, several stakeholder panels in different countries were organized to include the end users' opinions and to assure the usability of the final tool.
\end{abstract}

Keywords: radiological emergency / stakeholder / MCDA / decision support / uncertainty / CONFIDENCE

\section{Introduction}

The CONFIDENCE project (COping with uNcertainties For Improved modelling and DEcision making in Nuclear emergenCiEs) used a multidisciplinary approach dealing with many aspects of the radiological situation following the accidental release up to the decision making to evaluate, select and implement remediation strategies, including the viewpoints of stakeholders (Raskob et al., 2020). The decision aiding tool MCDA (Müller et al., 2020) is an extension to the JRODOS decision support system (DSS) using the results from the late phase models ERMIN (Charnock, 2016) and AgriCP (Charnock et al., 2018; Charnock et al., 2020) to support the decision making team in selecting the best possible remediation strategy in a given situation.

MCDA is recognised as a useful tool for transparent and coherent decision making among multiple alternatives for actions (strategies), for complex situations, supporting groups of stakeholders (e.g. decision makers) (Hiete et al., 2010). The transition and later phase of a radiological accident provide enough time for elicitation of the stakeholders' understanding and preferences as well as for the interpretation and discussion of the MCDA results.

The engagement of stakeholders in the development of countermeasure strategies, supporting a transition to long-term

\footnotetext{
*Corresponding author: tatiana.duranova@vuje.sk
}

recovery is an integral part of the CONFIDENCE project. (Montero et al., 2020; Raskob et al., 2020). National and international stakeholder panels were organised to provide the necessary input for the further development of the MCDA tool. This paper provides an overview of this process and the main conclusions.

\section{Scenario-based stakeholder workshops}

The MCDA tool improved with uncertainty modelling capabilities was presented in two national stakeholder panels (Slovak Republic and the Netherlands) and within the CONFIDENCE training course and dissemination workshop.

In all workshops, a transition phase scenario was presented to the stakeholders. JRODOS DSS provided supporting information in the form of dose and deposition maps, and areas with already implemented early countermeasures including evacuation, access and food restrictions. Different origins of the accident, as well as different weather ensemble conditions and source terms were assumed in the workshops. The results of the project HARMONE (Nisbet et al., 2017) were used for the development of strategies during the scenario preparation and for calculations with JRODOS DSS. Different countermeasure strategies were discussed, resulting in low to high volumes of waste, and with or without relocation, as indicated in Duranova et al. (2020a). The same HARMONE strategies formed the basis for the MCDA stakeholder discussions in all the workshops and the training course. 
The objective of the workshops was to gain experience in the process of establishing an optimal recovery strategy for the contaminated areas and the use of the MCDA tool to supporting this. In particular, discussions focussed on identifying the important criteria for decision-making, inclusion of uncertainties and eliciting and prioritizing stakeholder preferences. Facilitated discussion provided the floor for a thorough testing and use of MCDA as a decision aiding tool to help in choosing among the alternative strategies and in exchanging different opinions during the collaborative work.

Representatives of the authorities at national, regional and local level, ministries and state organisations, as well as experts representing decision-makers involved at different levels of the emergency preparedness, response and recovery management activities formed the discussion panels at the national workshops. The participants of the training course "Use of uncertain information by decision makers at the various levels within the decision making process and its communication" (Duranova et al., 2020b) and CONFIDENCE Dissemination workshop (Duranova et al., 2020a) formed the international stakeholder panels. The stakeholders dealt with urban decontamination and agricultural remediation issues and the impact of relocation.

The discussions were facilitated by experienced independent facilitators. The output of the MCDA tool was presented during the ongoing discussions. Changes in criteria or their weights were interactively observed and evaluated. The different opinions related to weights were investigated in the MCDA tool and then consolidated into one common agreement. Moreover, the language adaptation of the MCDA tool was used during the Slovak national stakeholder panel and the various graphical outputs were explored. More details on the national and international workshops can be found in Müller et al. (2019), van Asselt et al. (2020) and Duranova et al. (2020a, 2020b).

\section{Discussion}

Scenario-based workshops were used to discuss countermeasure strategies among stakeholders as well as social, ethical and communication aspects of uncertainty management (Charnock et al., 2020). The different possibilities of output visualization were presented and discussed. The presentation of outputs in the form of a text report was discussed as well and appreciated by participants. The report provides a summary of information describing strategies and preferences and could be used in addition to the graphical outputs in the decision making process. The Slovak adaptation of the report provided by the MCDA tool was also received very well by all participants at the Slovak national panel workshop.

The visualization of uncertainties as calculated by the ERMIN module of the JRODOS DSS was incorporated in the MCDA tool and different possible outputs were thoroughly discussed, especially in the Slovak stakeholder panel where stakeholders expressed their preferences regarding visualisation of outputs.

The participants of the workshops extensively discussed the criteria for use in the MCDA. Common criteria mentioned in both the national and international panels were: public

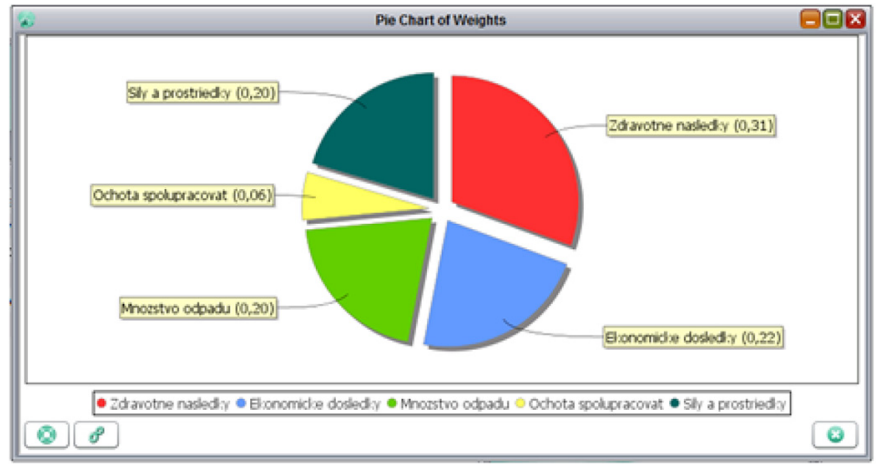

Fig. 1. Presentation of weights in the MCDA tool.

health expressed in terms of doses or number of averted cancers; costs including accommodation during relocation, compensation, loss of productivity, implementation of the clean-up strategy, waste transport and storage, cancer treatments; personal and technical resources (e.g. the number of workers needed for the realization of countermeasures); acceptance by the population and willingness to cooperate in the realization of a particular restoration strategy (self-help); attitude to the property and home; relation to receiving people during the relocation (stigmatization). Additionally, other criteria were mentioned, referring to issues such as wastes expressed by the (un)availability of storage places, which is conditioned by the amount of waste; political preferences; governmental issues; education and professionalism; and infrastructure (e.g. drinking water, education (school system), services, what can be provided and what is the timing).

If too many criteria are included in the MCDA, the process becomes rather complex. Therefore, stakeholders have to agree on the most relevant criteria when intent to use MCDA tool as a part of decision support system. The challenge in a one particular group of decision makers, when applying an MCDA, lies, therefore, in selecting the appropriate set of criteria and in their agreement on the respective weights of these criteria. The exact meaning of the criteria and the identified uncertainty therein is of prime importance when assigning values to criteria to select a recovery strategy. For example, very often the discussion was on what "protecting the health of the public" actually meant under the conditions of the accident, or what do the widely used "acceptance of countermeasures" or "feasibility" precisely mean.

After discussion, the stakeholders agreed on 4-6 criteria and assigned the values for those criteria. The values for quantitative criteria such as waste amount, number of workers needed and avoided doses could be quantified directly by the JRODOS DSS. The values for the qualitative criteria, as for example "Willingness of population to cooperate on strategy implementation", have to be estimated and agreed within the group and are more subjective (more details in van Asselt et al., 2020).

The MCDA tool allowed stakeholders to observe and evaluate changes in the criteria and their weights in an interactive manner. These can be presented differently. An example is illustrated in Figure 1.

After agreement on the initial weights for all the criteria, the ranking of the strategies is revealed and can be visualised to 
the participants. An example of such a visualisation is presented in Duranova et al. (2020a).

\section{Conclusions}

- Testing the MCDA tool helped to improve the final version of the tool.

After each panel meeting, stakeholders provided valuable advice and suggestions for improvement, which were followed to a large extent. Consequently, the tool became more and more tailored to stakeholders' needs.

- Stakeholders appreciated the usability of the tool; at the same time they raised some concerns.

Applying the method was technically simple, but choosing the right criteria was not that simple. There were concerns when selecting criteria, since they had to be rather independent from each other. The MCDA tool should be operated by qualified analysists who are well aware of the meaning of the criteria used. Additionally, it was pointed out that the application of the MCDA could oversimplify the process and could put too much trust into stakeholders for a certain suggested strategy.

- The tool helped to promote discussions amongst stakeholders.

Most impressive in all panels was the fact that the use of the MCDA tool was not focussed on producing a ranking, but much more on triggering the discussion to understand deeper the scenario and its defining criteria. Obvious is the discussion of different opinions on weights, which initially varied significantly. Less obvious is the different interpretation of the meaning of terms used, e.g. what "protection of people" or "acceptance of strategy" actually meant as the stakeholders had sometimes totally diverging views on these terms. As a very beneficial result, the discussion greatly helped to come to a consensus on different vague definitions or questions arisen before the actual decision making.

- The tool cannot replace human decision making.

It was definitely recognized by participants that the tool has a supportive character and the results provided by MCDA tool could not be taken directly as the final outcome. It was stressed that the final decision making will always be made by humans no matter how sophisticated a tool would be. Political decisions as one of the factors influencing the decision was pointed out and experienced in the discussions.

\section{Recommendations}

- Further testing of the MCDA will improve the tool.

It was suggested to use the tool in exercises especially related to the transition and recovery phase of an accident and in the emergency preparedness stage. Further testing of the MCDA tool in different scenarios and under different conditions to provide according recommendations in an emergency will enhance the tool.

- The purpose of the tool should be specified.
Stakeholders indicated that a discussion is needed to identify for which situations and for whom the tool would be usable.

- The tool should be used by trained experts.

Though the MCDA tool was easy to operate, it was suggested to have some trained expert operating it, while the stakeholders focussed on the discussion. The panel meetings also showed that a facilitated discussion would be very advisable to moderate any controversy.

Acknowledgement. The work described in this paper was conducted within the CONFIDENCE project which was part of the CONCERT project. This project has received funding from the Euratom research and training programme 20142018 under grant agreement No. 662287.

Disclaimer (Art. 29.5 GA). This publication reflects only the author's view. Responsibility for the information and views expressed therein lies entirely with the authors. The European Commission is not responsible for any use that may be made of the information it contains.

\section{References}

Charnock TW. 2016. Enhancement of the ERMIN urban dose and remediation model to account for physicochemical properties of contamination. Radioprotection 51(HS2): S105-S107.

Charnock TW, Andersson KG, Montero M, Trueba C. 2018. Addressing the uncertainties in urban/inhabited scenarios. CONCERT Deliverable 9.20. Available from https://www. concert-h2020.eu/en/Publications.

Charnock TW, Andersson K, Trueba C, Montero M. 2020. Uncertainties confronting stakeholders and decision-makers in planning intervention in urban and agricultural scenarios in the transition phase of a radiological emergency. Radioprotection 55 (HS1). https://doi.org/10.1051/radiopro/2020021.

Duranova T, Raskob W, Beresford NA, Korsakissok I, Montero M, Müller T, Turcanu C, Woda C. 2020a. CONFIDENCE dissemination meeting: Summary on the scenario based workshop. Radioprotection 55(HS1). https://doi.org/10.1051/radiopro/ 2020009.

Duranova T, Beresford NA, Perko T, Raskob W. 2020b. Education and training activities in the Euratom CONFIDENCE project. Radioprotection 55(HS1). https://doi.org/10.1051/radiopro/ 2020011.

Hiete M, Bertsch V, Comes T, Schultmann F, Raskob W. 2010. Evaluation strategies for nuclear and radiological emergency and post-accident management. Radioprotection 45(5): S133-S147.

Montero M, Sala R, Maitre M, Durand V, Nunes-Marques P, Reis M, Crouail P, Trueba C, Paiva I, Gil OM, Schneider T. 2020. Guidelines and recommendations for decision making during the transition phase. CONCERT Deliverable 9.24. Available from https://www.concert-h2020.eu/en/Publications.

Müller T, Duranova T, van Asselt E, Twenhöfel CJW, French S, Andersson KG, Haywood S, Oughton D, Smith JQ, Turcanu C. 2019. Report from stakeholder panels and workshops related to the application of the methods and tools developed in ST 0.1.6. CONCERT deliverable 9.36. Available from https://www.concerth2020.eu/en/Publications.

Müller T, Bai S, Raskob W. 2020. MCDA handling uncertainty. Radioprotection 55(HS1). https://doi.org/10.1051/radiopro/ 2020030. 
Nisbet A, Charnock T, Watson S. 2017. HARMONE Guidance handbook for recovery after a radiological incident. OPERRA Deliverable D5.55, $73 \mathrm{p}$.

Raskob W, Beresford NA, Duranova T, Korsakissok I, Mathieu A, Montero M, Müller T, Turcanu C, Woda C. 2020. CONFIDENCE: project description and main results.
Radioprotection 55(HS1). https://doi.org/10.1051/radiopro/ 2020008.

van Asselt ED, Twenhofel C, Duranova T, Smetsers R, Bohunova J, Müller T. 2020. Facilitating the decision-making process after a nuclear incident-Case studies in the Netherlands and Slovakia. (submitted 2020).

Cite this article as: Duranova T, van Asselt E, Müller T, Bohunova J, Twenhöfel CJW, Smetsers RCGM. 2020. MCDA stakeholder workshops. Radioprotection 55(HS1): S193-S196 